\title{
Stigma associated with mental illness: perspectives of university students in Qatar
}

\author{
This article was published in the following Dove Press journal: \\ Neuropsychiatric Disease and Treatment \\ 9 May 2017 \\ Number of times this article has been viewed
}

\author{
Monica Zolezzi ${ }^{1,2}$ \\ Nawal Bensmail ${ }^{2}$ \\ Farah Zahrah ${ }^{2}$ \\ Salma Mawfek Khaled ${ }^{3}$ \\ Tayseer El-Gaili ${ }^{4}$ \\ 'Clinical Pharmacy and Practice, \\ ${ }^{2}$ College of Pharmacy, ${ }^{3}$ Research Unit, \\ Social and Economic Survey Research \\ Institute, ${ }^{4}$ Student Counseling Center, \\ Qatar University, Doha, Qatar
}

Correspondence: Monica Zolezzi

Clinical Pharmacy and Practice, College of Pharmacy, Qatar University, Doha, Qatar

Tel +974 44035623

Fax +974 4403555 I

Email mzolezzi@qu.edu.qa
Background: Stigma in relation to mental illness is one of the main factors inhibiting people from seeking help. Studies have been undertaken looking into the knowledge, attitudes, and beliefs (KAB) about mental illness among residents in Qatar; however, none have looked specifically at students in higher education. The aim of this study was to understand the KAB toward mental illness among students at a Qatari university and determine if there are any differences based on gender, nationality, and college type.

Methods: A convenience sample of students from all genders, colleges, and nationalities was approached to participate in a survey that consisted of four sections: demographic, beliefs, attitudes, and help-seeking and treatment preferences associated with mental illness. Chi-square testing was performed to test for differences in the distribution of proportions of our primary outcomes (students' beliefs, attitudes, and help-seeking and treatment preferences).

Results: A total of 282 students completed the survey. The majority of the participating students were females (59.3\%), non-Qataris (64.3\%), and enrolled in science-based colleges $(62.7 \%)$. Beliefs reflecting poor mental health literacy, such as "medications to treat mental illness can cause addiction", "mental illness is not like any other illness", or that "mental illness is a punishment from God", were reported by a majority of students $(84.4 \%, 56.7 \%$, and $50.2 \%$, respectively). Stigmatizing attitudes that were endorsed by a majority of students included believing that people with mental illness cannot have regular jobs $(60.2 \%)$, that people with mental illness are dangerous $(65.7 \%)$, and that they would not marry someone with a mental illness $(88.9 \%)$. Additionally, $33.6 \%$ of students indicated they would be ashamed to mention if someone in their family or they themself, had a mental illness. A vast majority of students $(86.3 \%)$ indicated to prefer family and friend's support as treatment options. Significant differences in KAB about mental illness between genders, colleges, and college type were found only for a few items.

Conclusion: The findings of this study suggest that a high percentage of students reported KAB about mental illness, that are considered stigmatizing. Students' KAB about mental illness was consistent with that reported by the general population in Qatar. Nevertheless, the sample was small and as such, larger studies from a randomly selected population are needed to confirm these findings.

Keywords: knowledge, attitude and behavior, university students, stigmatization, mental illness

\section{Introduction}

Worldwide reports indicate that one in every four people suffer from a mental illness throughout their life, which accounts for $\sim 15 \%$ of the global disease burden. ${ }^{1,2}$ It is also known that many mental disorders can start at an early age, some as early as in childhood. ${ }^{2}$ According to Qatar's National Mental Health Strategy 2013-2018, the point prevalence of mental illnesses in Qatari nationals is $\sim 20 \%$, with females and young adults (aged 18-34 years) being the most affected. ${ }^{3}$ In a study conducted in 
Qatar, it was reported that generalized anxiety disorders and major depression were the most prevalent among Qatari nationals. ${ }^{4}$ Despite the fact that these disorders are frequently encountered, significant underutilization of mental health care services by patients who suffer from mental illness has been reported in the international literature, with nearly two-thirds never seeking attention from a trained or qualified health care professional. ${ }^{1}$

Stigma has been defined as a "sign of disgrace or discredit, which sets a person apart from others". 5 Stigma in mental illness can be described as a cluster of negative attitudes and beliefs that motivate fear, reject, avoid, and discriminate against people who have mental illnesses. ${ }^{5}$ Attitudes toward mental illness are also shaped by the individuals' mental health literacy; that is, the knowledge and beliefs about mental disorders which aid their recognition, management, or prevention. ${ }^{6}$ Beliefs about mental illness are also shaped by knowing and interacting with someone living with mental illness, the media, and cultural stereotypes. ${ }^{5-8}$

As such, beliefs and attitudes about mental illness influence how people interact with those with a mental illness, as well as how they experience and express their own emotional problems and psychological distress and whether they disclose these symptoms and seek care. In mental illness, stigma is one of the main factors that inhibit people from seeking help. ${ }^{9}$ Stigmatization occurs globally and is prevalent not only among the general public, but even among health care professionals. ${ }^{10,11}$ Although there are well-known manuals with validated criteria which are well known and used internationally for diagnosing mental illnesses (such as the Diagnostic and Statistical Manual for Mental Disorders ${ }^{12}$ and the International Classification of Diseases), ${ }^{13}$ treatment seeking is influenced by the individual's mental health literacy which is also culturally shaped, as the manifestations of any particular mental disorder may vary with the culture in which it presents. ${ }^{14}$ For example, in Malaysia, belief of psychiatric patients in supernatural causes was associated with greater use of traditional healers and poorer compliance with medication. ${ }^{15}$ Understanding the role of these influential factors is important in order to implement culturally appropriate strategies to manage mental disorders.

Qatar is a small country and its population comprises mostly non-Qatari expatriate workers of diverse ethnicity, predominantly from the Indian subcontinent and Arabs from various nationalities (mostly Egyptians, Syrians, Jordanians, Lebanese, Palestinians, Tunisians, and people from other Gulf countries). ${ }^{16}$ Considering this demographic pattern, studies to explore differences in the knowledge, attitudes, and beliefs $(\mathrm{KAB})$ about mental illness among residents in Qatar have been undertaken. ${ }^{17-19}$ In one of these studies in the general population, authors found that Qataris had poorer knowledge and more negative attitudes toward mental illnesses and their treatment, compared to non-Qataris. ${ }^{19}$

There are no current published studies examining the $\mathrm{KAB}$ toward mental illness among university students in Qatar. Considering that in Qatar, students in higher education comprise mostly young adults (the majority being females) in the age range of $18-34$ years, ${ }^{4}$ who are also the most vulnerable for mental illness, ${ }^{3}$ it is important to examine if findings similar to those reported by the general population in Qatar are seen among university students. We hypothesized that university students in Qatar were better informed about mental illness than the general population and aimed at establishing if, within this population, there were any differences in KAB between Qataris and non-Qataris, females and males, and those attending science-based and non-science-based colleges.

\section{Methods}

A cross-sectional survey of students at Qatar University (QU) was carried out during the fall semester in 2015. The study was approved by the Institutional Review Board at QU (reference number: QU-IRB 501-E/15).

\section{Sample}

All undergraduate and graduate students at QU were eligible for inclusion, provided they were able to understand English. Researchers visited all colleges at QU and explained the study and its objectives to prospective participants. Informed consent was obtained from each student before the survey was completed.

\section{Questionnaire}

An adapted version of a questionnaire used to survey beliefs and attitudes toward mental illness in a sample of the general population in Qatar was used. ${ }^{19}$ Questions were changed considering the aims of this study and the student population that was being targeted. The final questionnaire consisted of four parts (Supplementary material):

1. Participants' demographic characteristics (such as age, nationality, marital/living/financial status, educational background, and some information about the students' parents).

2. Participants' beliefs associated with mental illness. Questions in this section focused on the etiology of mental illness in addition to beliefs related to treatment. 
3. Participants' attitudes toward individuals with mental illness. Questions in this section focused on the students' willingness to interact with individuals with mental illness, in order to identify any stigmatizing behavior on their part.

4. Participants' help-seeking preferences when it comes to management of mental illness. Questions in this section focused on students' approaches to treatment for mental illness, including treatment preferences.

The adapted version of the questionnaire was piloted on a sample of 20 randomly selected QU students from both genders in order to establish face validity, readability, clarity of questions, as well as time needed to complete the survey.

\section{Data collection and analyses}

A convenience (nonrandom sampling) approach was used. Researchers approached students from all genders, colleges, and nationalities at their respective colleges during the fall and spring semesters of the 2015-2016 academic year (November 2015-May 2016). An information sheet on the study was provided to the students, together with a consent form to give students more information about the study and its objectives. Consenting students were offered the choice for completing the questionnaire online (through SurveyMonkey ${ }^{\circledR}$ accessible via an $\mathrm{iPad}^{\circledR}$ computer) or were given paper-based questionnaires. Data from the paper-based questionnaires were later entered into SurveyMonkey by the researchers. Once data from all surveys were available, these were exported into SPSS ${ }^{\circledR}$ (version 21) for analysis.

Descriptive statistics were performed and reported as frequencies and percentages. The proportions (and percentages) were calculated based on valid responses, that is, nonmissing values and responses other than refusals. The latter were treated as missing and were not counted as part of the denominator for the corresponding proportion. "I don't know" answers were treated as valid responses when calculating the proportions of those endorsing stigmatizing statements with respect to beliefs and attitudes toward mental illness. Chi-square testing was performed to test for differences in the distribution of proportions of our primary outcomes (students' beliefs, attitudes, help-seeking and treatment preferences) between groups based on the following.

\section{Nationality}

Given the diversity in nationalities among non-Qatari students at QU (which for the most part include Egyptians, Syrians, Jordanians, Persians, Pakistanis, Sudanese, Indians, and Omanis, among others), these were grouped together in order to provide more robust results when analyzing differences in KAB among Qatari and non-Qatari students.

\section{Gender}

Considering that the majority of students at QU comprise females, it was important to analyze differences in KAB among males and females.

\section{College type}

Assuming that students in science programs would be better informed about mental illness, QU colleges were classified as science-based (SB; colleges of medicine, engineering, pharmacy, and general sciences) and non-science-based (NSB; colleges of law, business, education, arts, and Islamic studies) to explore if any differences in $\mathrm{KAB}$ about mental illness exist among the students attending these two types of colleges.

Statements about beliefs were classified further to provide an indication of the students' level of awareness about mental health. Depending on the statement, a "yes" or "I don't know" answer was considered as reflecting poor awareness about mental illness in the part of the student (eg, the statement "do you think mental illness is due to possession by evil spirits?"); whereas for other statements, a "no" or "I don't know" answer would also be considered as being poorly aware about mental illness (eg, the statement "genetic inheritance can be the cause of mental illness"). Statements reflecting poor awareness were also considered to be potentially stigmatizing. A similar classification was used for the statements about attitudes toward people with mental illness. Depending on the statement, a "yes" or "I don't know" answer was considered as stigmatizing (eg, the statement "people with mental illness are dangerous"); whereas for other statements, a "no" or "I don't know" answer would also be considered as stigmatizing (eg, the statement "would you be willing to maintain friendship with someone with a mental illness?").

Multiple answers were allowed only for the section exploring students' help-seeking and treatment preferences. The level of significance for statistical tests was set a priori at $P<0.05$.

\section{Results}

A total of 282 students completed the survey. A summary of the characteristics of the study sample is presented in Table 1. The majority of the student participants were females $(59.3 \%)$, non-Qataris $(64.3 \%)$, aged between 18 and 24 years $(85.8 \%)$, single $(92.5 \%)$, and living with their 
Table I Demographic characteristics of the studied sample $(\mathrm{N}=282)$

\begin{tabular}{|c|c|}
\hline Students' characteristics & n (\%) \\
\hline \multicolumn{2}{|l|}{ Gender } \\
\hline Male & I I 4 (40.7) \\
\hline Female & $116(59.3)$ \\
\hline \multicolumn{2}{|l|}{ Nationality } \\
\hline Qatari & $100(35.7)$ \\
\hline Non-Qatari & $180(64.3)$ \\
\hline \multicolumn{2}{|l|}{ Age group, years } \\
\hline$<18$ & $17(6.0)$ \\
\hline $18-24$ & $24 I(85.8)$ \\
\hline $25-30$ & $20(7.1)$ \\
\hline$>30$ & $3(1.1)$ \\
\hline \multicolumn{2}{|l|}{ Social status } \\
\hline Married & $21(7.5)$ \\
\hline Single & $259(92.5)$ \\
\hline \multicolumn{2}{|l|}{ Living status } \\
\hline Alone & $7(2.5)$ \\
\hline With family & $27 \mid(96.8)$ \\
\hline With friends & $2(0.7)$ \\
\hline \multicolumn{2}{|l|}{ Academic year } \\
\hline First & $69(24.6)$ \\
\hline Second & $76(27.0)$ \\
\hline Third & $64(22.8)$ \\
\hline Fourth & $37(13.2)$ \\
\hline Fifth & $14(5.0)$ \\
\hline Post-graduate & $21(7.5)$ \\
\hline \multicolumn{2}{|l|}{ College } \\
\hline Science based & $177(62.7)$ \\
\hline Arts and sciences & $37(13.1)$ \\
\hline Pharmacy & $21(7.4)$ \\
\hline Engineering & $79(28.0)$ \\
\hline Medicine & $40(14.2)$ \\
\hline Non-science based & $105(37.2)$ \\
\hline Business & $57(20.2)$ \\
\hline Law & $15(5.3)$ \\
\hline Education & $25(8.9)$ \\
\hline Islamic studies & $8(2.8)$ \\
\hline \multicolumn{2}{|l|}{ History of mental illness } \\
\hline Yes & 45 (18.9) \\
\hline No & $169(71.0)$ \\
\hline I don't know & $24(10.1)$ \\
\hline
\end{tabular}

families (96.8\%). The majority of participants were enrolled in SB programs (62.7\%), most of them at the College of Engineering (28.0\%). The majority $(71.0 \%)$ of the students who completed the survey indicated that they did not have a history of mental illness or had ever been told they have a mental illness.

\section{Students' knowledge and beliefs} associated with mental illness

The percent responses of the students' beliefs regarding mental illness are summarized in Table 2. Students' beliefs

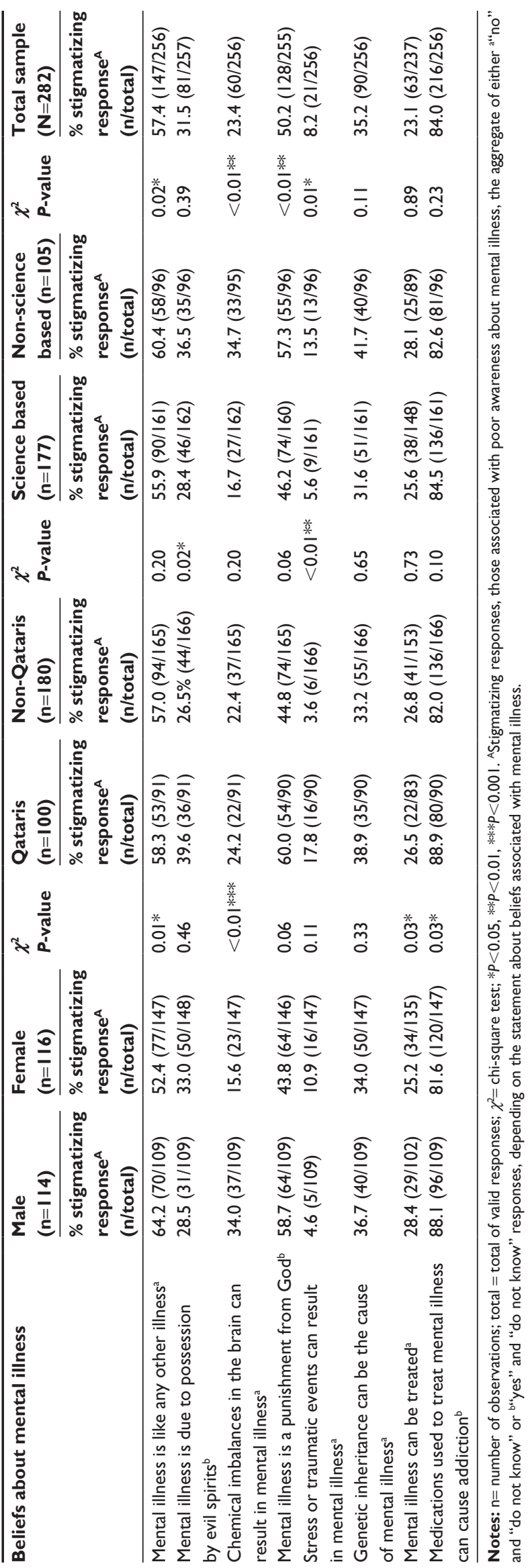


reflecting poor awareness of mental illness included: "mental illness is like any other illness" ( $57.6 \%$ of students responding "no" and "I don't know"), "mental illness is a punishment from God" (50.2\% of students responding "yes" and "I don't know"), and "medications to treat mental illness can cause addiction" ( $84.4 \%$ of students responding "yes" and "I don't know"). Over a quarter of the students (26.6\%) indicated that they believed mental illness cannot be treated.

\section{Students' attitudes toward mental illness}

Table 3 shows the percentage of students endorsing stigmatizing attitudes toward the mentally ill. The majority of students indicated believing that people with mental illness cannot have regular jobs (60.2\% answering "no" or "I don't know"), that people with mental illness are dangerous (65.7\% answering "yes" or "I don't know"), and that they would not marry someone with a mental illness $(88.9 \%$ answering "no" or "I don't know"). Additionally, 33.6\% indicated they would be ashamed to mention if someone in their families or themselves had a mental illness.

\section{Students' help-seeking and treatment preferences in relation to mental illness}

As summarized in Table 4, the vast majority of students $(84.5 \%)$ indicated that they would ask help from family members and $81.7 \%$ would consult a psychiatrist. Close to half of the students would consider seeking help from a pharmacist (44.8\%) and only about one-third (37.3\%) from a nurse. With respect to mental health treatments, the majority of students preferred support from family and friends $(83.6 \%)$. Individual counseling (68.6\%) and medications (68.1\%) were among the top preferred treatments. Less than a quarter of the students indicated that marriage could be a treatment for mental illness (20.5\%). Only $35.9 \%$ of the students were aware of the services provided by the university's Student Counseling Center (SCC).

\section{Gender differences}

As summarized in Tables 2-4, significantly more male (64.2\%) than female (52.4\%) students believed that "mental illness is like any other illness" $(P=0.01)$, that "chemical imbalances can result in mental illness" (male $=34.0 \%$, female $=15.6 \% ; P<0.01$, that "mental illness can be treated" ( male $=28.4 \%$, female $=25.2 \% ; P=0.03$ ), and that "medications to treat mental illness can cause addiction" ( male $=88.1 \%$, female $=81.6 \% ; P=0.03)$. Significantly more male than female students reported to be "willing to marry someone with a mental illness" ( male $=93.4 \%$,

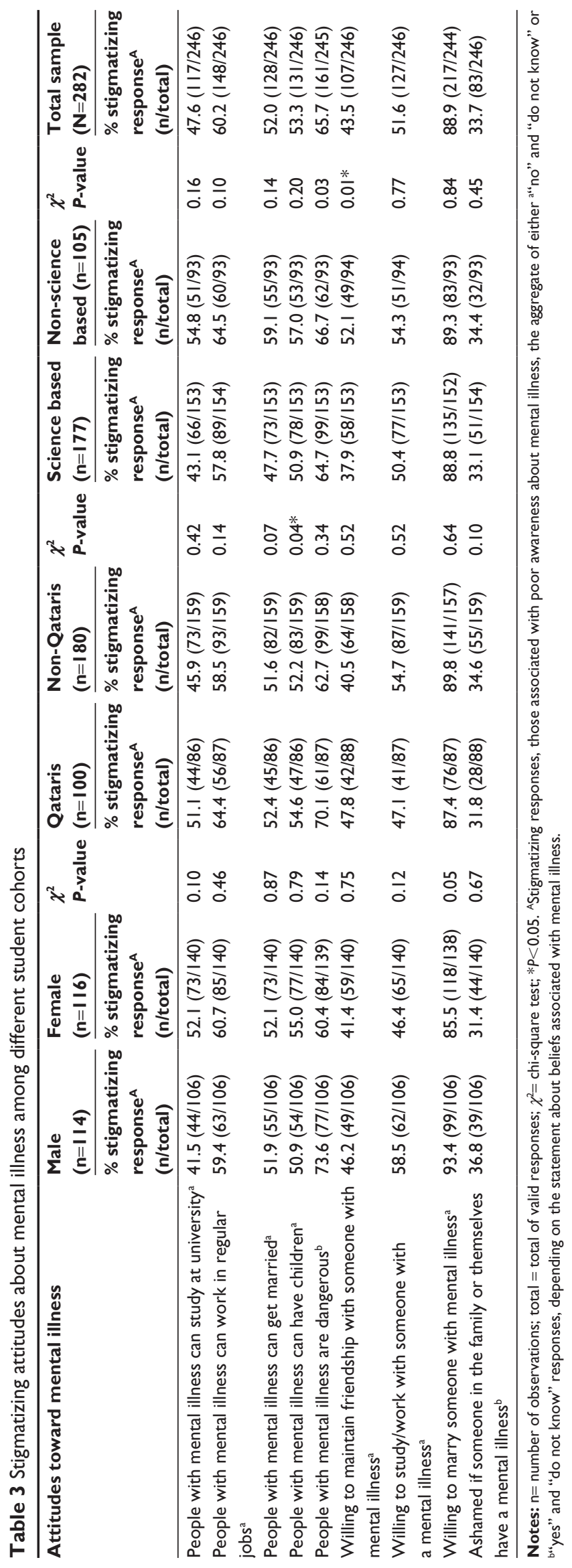




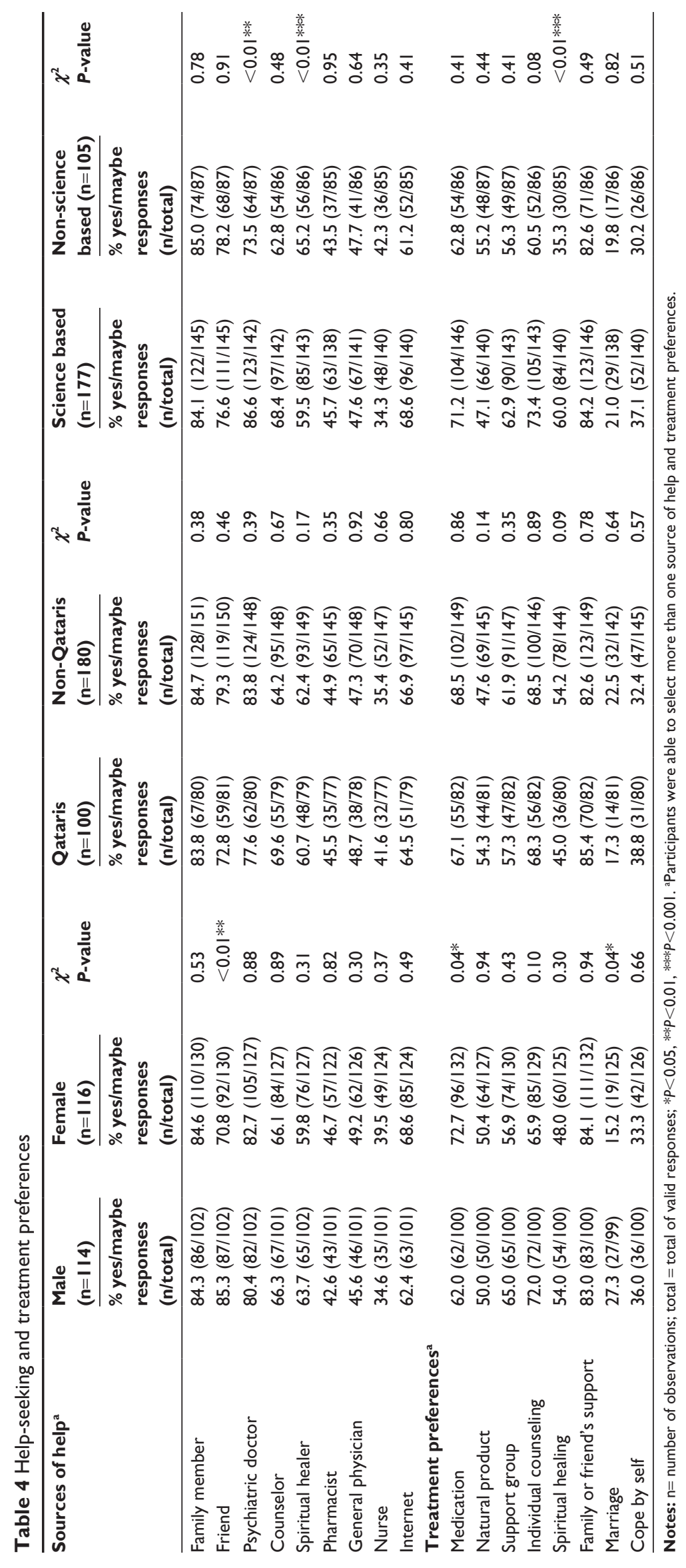


female $=85.5 \% ; P=0.05)$, would ask for help from friends when confronted with a mental health problem ( male $=85.3 \%$, female $=70.8 \% ; P<0.01$ ), but significantly more females $(72.7 \%)$ than males $(62.0 \%)$ would use medications to treat mental illness $(P=0.04)$. Significantly more male $(27.3 \%)$ than female $(15.2 \%)$ students reported that they would consider marriage as a treatment option for dealing with mental health problems $(P=0.04)$.

\section{Qatari versus non-Qatari differences}

Significantly more Qatari (39.6\%) than non-Qatari (26.5\%) students believed that "mental illness is the result of possession of evil spirits" ( $P=0.02)$. Significantly more Qatari (17.8\%) than non-Qatari (3.6\%) students believed that "stress or traumatic events can result in mental illness" $(P<0.01)$, and that "people with mental illness can have children" (Qatari $=54.6 \%$, non-Qatari $=52.2 \% ; P=0.04$ ). No significant differences were found in help-seeking or treatment preferences for mental health problems between Qatari versus non-Qatari students.

\section{Differences among students in SB versus NSB colleges}

Significantly more students attending SB (44.1\%) versus NSB (39.6\%) colleges believed that "mental illness is like any other illness" $(P=0.02)$, that "chemical imbalances in the brain can result in mental illness" ( $\mathrm{SB}=83.3 \%, \mathrm{NSB}=65.3 \%$; $P<0.01$ ), and that "stress or traumatic events can result in mental illness" ( $\mathrm{SB}=94.4 \%, \mathrm{NSB}=86.5 \% ; P=0.01)$. Significantly more students in NSB colleges indicated they perceive people with mental illness as dangerous (NSB $=66.7 \%$, $\mathrm{SB}=64.7 \% ; P=0.03)$, but were also significantly more willing to maintain friendship with someone with mental illness (NSB $=52.1 \%, \mathrm{SB}=37.9 \% ; P=0.01$ ). Significantly more students in SB colleges reported they would seek help from a psychiatric doctor ( $\mathrm{SB}=86.6 \%, \mathrm{NSB}=73.5 \% ; P<0.01$ ), and significantly more students in NSB colleges reported they would seek help from a spiritual healer (NSB $=65.2 \%$, $\mathrm{SB}=59.5 \% ; P<0.01)$.

\section{Discussion}

Although similar studies in the general population in Qatar have been published, ${ }^{17-19}$ to the best of our knowledge, this is the first exploring KAB about mental illness among university students. In contrast to what was hypothesized, university students' stigmatizing beliefs were similar to those reported in the study by Bener and Ghuloum in the general population. ${ }^{19}$ Even though university students may be considered to be well educated, several beliefs reflecting poor mental health literacy were highly prevalent, such as "medications to treat mental illness can cause addiction", "mental illness is not like any other illness", and "mental illness is a punishment from God". Similar views were reported by medical students and the general public in Oman, who rejected a genetic factor as the cause of mental illness and rather favored the role of spiritual factors. ${ }^{20}$ These findings suggest that other factors, such as some cultural and religious teachings, possibly influence beliefs about the origins and nature of mental illness.

The sample of university students in our study also shared similar negative attitudes toward people with mental illness as those reported by the general population in Qatar. ${ }^{19}$ Stigmatizing attitudes, such as that mentally ill individuals cannot hold regular jobs, or that they would not be willing to work with mentally ill individuals, were also highly prevalent in our study. In the Omani study, the majority of students also reported other negative attitudes such as that mentally ill individuals should not have children, get married, or maintain contact with the public. ${ }^{20}$ Interestingly, more than half of QU students were comfortable with maintaining a friendship with someone who is mentally ill, an attitude that was reported by only less than a quarter of participants in the Qatar-based study in the general population. ${ }^{19}$ It is possible that this positive attitude by students compared to the general population is related to age. Other authors have found that older people had more negative attitudes (specifically social distancing) toward the mentally ill than their younger counterparts. ${ }^{21}$

Another important finding in our study was in relation to nationality differences in beliefs and attitudes toward people with mental illness. Qatari students in our study sample were less aware of the causes of mental illness and showed less favorable attitudes toward individuals with mental illness, compared to non-Qatari students. A possible explanation for these differences could be related to non-Qatari students having been exposed to other sociocultural environments, which may in turn contribute to an increased awareness about mental illness. Other authors with similar findings have also suggested that individuals who have lived or have had upbringing in other more "westernized" Arab societies may become more aware of mental illness and its treatments. ${ }^{22}$ Our results suggests that ethnic backgrounds can influence people's knowledge and attitudes toward mental illness, and support existing literature that mental illness is a concept deeply tied to culture. . $^{719,22}$

The majority of QU students prefer seeking the support from family and friends when facing psychological problems. Most students also held misconceptions regarding treatment, 
such as believing that medications to treat mental illness can cause addition, and mostly also appeared to underestimate the importance of seeking professional help for mental or psychological problems. Many studies in the Middle East have suggested that individuals may rather seek social support from family members or friends when faced with mental illness rather than seeking professional help. ${ }^{22-25}$ This helpseeking attitude has been attributed to the Arab culture and among individuals of Muslim faith, who have a strong family bond, and thus, involving non-family members in mental health issues, which implicates revealing familial or personal issues, is less acceptable than in western societies. ${ }^{23,26-28}$ Misconceptions (such as believing that medications used to treat mental illnesses are associated with addiction reported by $84.5 \%$ of students in our study) and lack of awareness (such as being unaware of the services provided by the university's Student Counseling Center) may be influencing students to rely more on friends and family for mental health support. These findings are consistent with those from another study conducted in the United Arab Emirates, in which most students were unaware of both individual and group counseling and psychological consultations provided on campus. ${ }^{23}$ These findings highlight the need for educational interventions in this population to increase awareness about the importance of pharmacologic treatment and for improving access to mental health services within the university. ${ }^{29}$

\section{Differences among different student cohorts}

Overall, male QU students appear to be better informed about the causes of mental illness than QU female students. However, overall attitudes toward mental illness did not appear to be significantly affected by gender. An exception to this finding was that QU male students appeared to be more likely than QU female students to marry someone with a mental illness, and also more males than females would consider marriage as a preferred treatment. Other studies in the Middle East have reported that females believe more in modern treatments as they were more inclined to consult professional mental health services for treatment. ${ }^{22,25,30}$ In our study, significantly more female students also preferred medication to treat mental illness. Combined, these results suggest female students may have a stronger inclination toward more modern treatments in comparison to their male counterparts.

Surprisingly, students in NSB colleges showed an overall favorable KAB about mental illness compared to those in SB colleges, except for believing that mental illness is a punishment from God. Results of studies in other universities in the
Middle East have shown conflicting results in this regard. For example, in a study in Jordan, medical students reported more favorable attitudes toward people with mental illness, ${ }^{24}$ while a study in Oman reported that both medical students and the public rejected a genetic factor as the cause of mental illness and rather favored the role of spirits. ${ }^{20}$ Combined, these results suggest that social and cultural underpinnings are more likely to influence students' KAB about mental illness than the college where these students receive their education.

\section{Study limitations}

The nationality variable was Qatari and non-Qatari. However, the non-Qataris represent a heterogeneous group from various nationalities, both from Arabic and non-Arabic speaking countries. Hence, there is a definite diversity within this group in their cultural beliefs and attitudes such that lumping them into one category may not be appropriate. Findings from this study are based on a convenience sample. Therefore, the proportion estimates and confidence intervals may not have their presumed frequency properties. Furthermore, the nonrandom nature of the sample may impact the validity and generalizability of our findings. In fact, the distributional properties of the study sample differed substantially from what is known about QU students' population, including that $65 \%$ of the actual population are Qataris, while the reverse was found to be true in our sample with approximately two-thirds reported being non-Qataris. It is also known that females make up $\sim 70 \%$ of the students at QU, but were underrepresented in our sample at $53.3 \%$. With this in mind, it is possible that our estimates of the proportions related to lack of knowledge about the roots of mental illness and corresponding negative attitudes and beliefs about people with mental illness may be an underestimate of the actual proportions in the larger QU student population. Multiple statistical tests were conducted simultaneously, which increases the type I error. This may explain why some results were statistically significant, though the differences between the groups were small. Therefore, caution must be taken when interpreting the results. Multiple responses were allowed for the main questions of interest in this study. This approach has the advantage of approximating real-life experiences by allowing participants to express multiple points of view toward the subject matter. Nevertheless, this type of question design poses analytical challenges. Specifically, the use of traditional Pearson's chi-squared tests is limited in the presence of multiple-response questions because of within-subject dependence among responses. ${ }^{31}$ While sophisticated statistical approaches that deal with this issue are beyond the scope of the paper, we acknowledge that 
allowing multiple answers makes the results more difficult to interpret, and is thus a limitation of this study. Finally, due to the self-reported nature of the data, it is impossible to rule out social desirability bias. This type of bias can lead to participants choosing answers that they perceive as being more socially desirable and are not an actual representation of their perceptions. For example, they might have reported to be more willing to interact with mentally ill individuals, when in reality, they are not comfortable with such behavior; hence, this would result in falsely elevated nonstigmatizing attitudes toward people with mental illness.

\section{Conclusion}

The results of this study indicate that the students' beliefs about mental illness were interrelated to their attitudes, both of which set the stage for how they interact with people with mental illness as well as how they seek help and support when faced with a psychological problem themselves. The findings of this study were similar and consistent with those found in the general population in Qatar, supporting existing literature that attitudes and beliefs about mental illness are shaped by knowledge and cultural stereotypes. Nevertheless, the sample was small and as such, larger studies from a randomly selected population are needed in order to make more conclusive remarks. Because knowledge and attitudes are fundamental for reducing stigmatization, the study findings are important for determining the need for culturally specific targeted stigma intervention programs at the university level.

Treatment preferences were variable among students, although most students were not aware of the psychiatric help services provided by the university. These results suggest that strategies at the university to promote help-seeking in the part of the students are also needed. This could be done through awareness campaigns promoted by the SCC to educate students about the causes and the available treatment options for mental illnesses. Such a strategy is likely to also increase awareness of students about the services provided by the SCC. A collaborative strategy between the College of Pharmacy at QU and the SCC is also being planned to help support the SCC in educating QU students about medications. Future studies can find if awareness campaigns can have positive outcomes in terms of decreasing misperceptions among QU students in relation to mental illness.

\section{Acknowledgments}

Many thanks to all the students who accepted to participate in our study. We also acknowledge the help from Ahmed Al-Kaddour in survey distribution and data collection.

\section{Disclosure}

The authors report no conflicts of interest in this work.

\section{References}

1. World Health Organization (WHO). Mental disorders affect one in four people [Internet]. WHO; 2015 [cited March 21, 2017]. Available from: http://www.who.int/whr/2001/media_centre/press_release/en/. Accessed March 22, 2017.

2. National Alliance on Mental Illness (NAMI). Mental Health Conditions [Internet]. NAMI; 2015 [cited March 21, 2017]. Available from: https:// www.nami.org/Learn-More/Mental-Health-Conditions. Accessed March 22, 2017.

3. Supreme Council of Health (SCH). Qatar National Mental Health Strategy Qatar [Internet]. SCH; 2015 [cited March 21, 2017]. Available from: http://nhsq.info/app/media/1166. Accessed March 22, 2017.

4. Bener A, Ghuloum S, Dafeeah E, Al-Yazidi T, Mustapha A, Zakareia A. Lifetime prevalence of common mental disorders in Qatar: using WHO composite international diagnostic interview (WHO-CIDI). Int J Clin Psychiat Ment Health. 2014;2(1):38-46.

5. Byrne P. Stigma of mental illness and ways of diminishing it. $A d v$ Psychiatr Treat. 2000;6(1):65-72.

6. Jorm AF. Mental health literacy. Public knowledge and beliefs about mental disorders. Br J Psychiaty. 2000;177:396-401.

7. Rao D, Feinglass J, Corrigan P. Racial and ethnic disparities in mental illness Stigma. J Nerv Ment Dis. 2007;195(12):1020-1023.

8. Corrigan PW, Markowitz FE, Watson AC. Structural levels of mental illness: stigma and discrimination. Schizophr Bull. 2004;20(3):481-491.

9. Thornicroft G. Stigma and discrimination limit access to mental health care. Epidemiol Psichiatr Soc. 2008;17(1):14-19.

10. Thornicroft G, Brohan E, Rose D, Sartorius N, Leese M. Global pattern of experienced and anticipated discrimination against people with schizophrenia: a cross-sectional survey. Lancet. 2009;373(9661):408-415.

11. Corrigan PW, Watson AC. Understanding the impact of stigma on people with mental illness. World Psychiatry. 2002;1(1):16-20.

12. American Psychiatric Association (APA). The Diagnostic and Statistical Manual of Mental Disorders. 5th ed. Washington, DC: APA; 2013.

13. World Health Organization (WHO). International Classification of Diseases and Related Health Problems. 10th revision. Geneva: WHO; 1992.

14. Kirmayer LJ. Cultural variations in the response to psychiatric disorders and psychological distress. J Clin Psychiatry. 2001;62(Suppl 13):22-28.

15. Razali SM, Khan UA, Hasanah CI. Belief in supernatural causes of mental illness among Malay patients: impact on treatment. Acta Psychiatr Scand. 1996;94(4):229-233.

16. Snoj J. Population of Qatar by nationality -2017 report. [Internet, Feb 7, 2017]. [cited March 21, 2017]. Available from: http://priyadsouza.com/population-of-qatar-by-nationality-in-2017/.

17. Bener A, Ghuloum S. Gender differences in the knowledge, attitude and practice towards mental health illness in a rapidly developing Arab society. Int J Social Psychiatry. 2010;57(5):480-486.

18. Ghuloum S, Bener A, Burgut F. Epidemiological survey of knowledge, attitudes, and health literacy concerning mental illness in a national community sample: a global burden. J Prim Care Community Health. 2010;1(2):111-118.

19. Bener A, Ghuloum S. Ethnic differences in the knowledge, attitude and beliefs towards mental illness in a traditional fast developing country. Psychiatria Danubina. 2011;23(2):157-164.

20. Al-Adawi S, Dorvlo A, Al-Ismaily S, et al. Perception of attitude towards mental illness in Oman. Int J Soc Psychiatry. 2002;48(4):305-317.

21. Yuan Q, Abdin E, Picco L, et al. Attitudes to mental illness and its demographic correlates among general population in Singapore. PLoS One. 2016;11(11):e0167297.

22. Al-Krenawi A, Graham JR, Al-Bedah EA, Kadri HM, Sehwail MA. Crossnational comparison of Middle Eastern university students: help-seeking behaviors, attitudes toward helping professionals, and cultural beliefs about mental health problems. Community Ment Health J. 2009;45(1):26-36. 
23. Al-Darmaki F. Needs, attitudes toward seeking professional help, and preferred sources of help among Emirati College students. J Int Couns Educ. 2011;3(1):39-57.

24. Rayan A, Jaradat A. Stigma of mental illness and attitudes toward psychological help-seeking in Jordanian university students. Res Psychol Beha Sci. 2016;4(1):7-14.

25. Bilican F. Help-seeking attitudes and behaviors regarding mental health among Turkish college students. Int J Ment Health. 2013; 42(2):43-59.

26. Dardas LA, Simmons LA. The stigma of mental illness in Arab families: a concept analysis. J Psychiatr Ment Health Nurs. 2015;22(9): 668-679.

27. Karam EG, Mneimneh ZN, Karam AN, et al. Prevalence and treatment of mental disorders in Lebanon: a national epidemiological survey. Lancet. 2006;367(9515):1000-1006.
28. Karim S, Saeed K, Rana MH, Mubhashar MH, Jenkins R. Pakistan mental health country profile. Int Rev Psychiatry. 2004;16(1-2):83-92.

29. Wright A, McGorry PD, Harris MG, Jorm AF, Pennell K. Development and evaluation of a youth mental health community awareness campaign. The Compass Strategy. BMC Public Health. 2006;6:215.

30. Al-Krenawi A, Graham JR, Kandah J. Gendered utilization differences of mental health services in Jordan. Community Ment Health J. 2000; 36(5):501-511.

31. Thomas RD, Decady YJ. Analyzing categorical data with multiple responses per subject. Statistics Society of Canada: proceedings of the Survey Methods Section; 121-130, 2000. 


\section{Supplementary material}

\section{Qatar University students' beliefs and preferences for the management of mental illness and psychological problems}

Dear participant,

Thank you very much for agreeing to participate in this survey. The questionnaire is divided into 3 parts. Please try to answer ALL the questions to the best of your ability and as completely as possible.

\section{Part 1: Demographics}

1. Gender:

$\square$ Male

2. Nationality:

$\square$ Qatari

3 Age group (years):
$\square<18$
4. Social status:

$\square$ Married

$\square$ Married
Female

Non-Qatari $\square$ Yes $\square$ No

6. Academic year:
$\square$ First year
$\square$ Second year

7. College:
$\square$ Arts \& sciences
$\square$ Engineering
Pharmacy
$\square$ Medicine

8. Parent's working status:

Father:

Mother:

9. Parent's highest education level:

Father: $\quad \square$ Primary school

Mother:

10. Living status:

$\square$ Alone

$\square$ Primary school

11. Do you have a scholarship:

$\square$ Yes

With parents/family

$\square$ No $\square$ 25-30 $\square>30$

$\square$ Third year $\quad \square$ Fourth year

$\square$ Fifth year

Post-graduate

$\square$ Business $\square$ Law

Education

Sharia

Part 2: Beliefs associated with mental illness (select only ONE answer, "Yes", "No", or "I don't know")

\begin{tabular}{|c|c|c|c|}
\hline Questions & Yes & No & I don't know \\
\hline 1. Do you think that mental illnesses are like any other illness? & & & \\
\hline 2. Do you think mental illness is due to possession by evil spirits? & & & \\
\hline 3. Do you think chemical imbalances in the brain can cause mental illness? & & & \\
\hline 4. Do you think mental illness can be punishment from God? & & & \\
\hline 5. Do you think stress in daily life, traumatic event, or shock can cause mental illness or psychological pr & & & \\
\hline 6. Do you think genetic inheritance may be the cause of mental illness? & & & \\
\hline 7. Do you think medications used to treat mental illness cause addiction? & & & \\
\hline 8. Do you think mental illness can be treated (Select only ONE answer: "Yes", "No", or "I don’t know") & & & \\
\hline
\end{tabular}


Part 3: Attitudes associated with mental illness (select only ONE answer, "Yes", "No", or "I don’t know”)

\begin{tabular}{|c|c|c|c|}
\hline Question: & Yes & No & I don't know \\
\hline \multicolumn{4}{|l|}{ 1. Do you think people with mental illness can live normal lives like: } \\
\hline \multicolumn{4}{|l|}{ a. Study at University } \\
\hline \multicolumn{4}{|l|}{ b. Work in regular jobs } \\
\hline \multicolumn{4}{|l|}{ c. Get married } \\
\hline \multicolumn{4}{|l|}{ d. Have children } \\
\hline \multicolumn{4}{|l|}{ 2. Do you think people with mental illness are dangerous? } \\
\hline \multicolumn{4}{|l|}{ 3. Would you be willing to: } \\
\hline \multicolumn{4}{|l|}{ a. Maintain a friendship with someone with mental illness } \\
\hline \multicolumn{4}{|l|}{ b. Study or work with someone with mental illness } \\
\hline \multicolumn{4}{|l|}{ c. Marry someone with mental illness } \\
\hline $\begin{array}{l}\text { 4. Are you ashamed to mention that someone in your family or yourself have a mental illness } \\
\text { and/or experienced psychological problems? }\end{array}$ & & & \\
\hline
\end{tabular}

Part 4: Help-seeking and treatment preferences

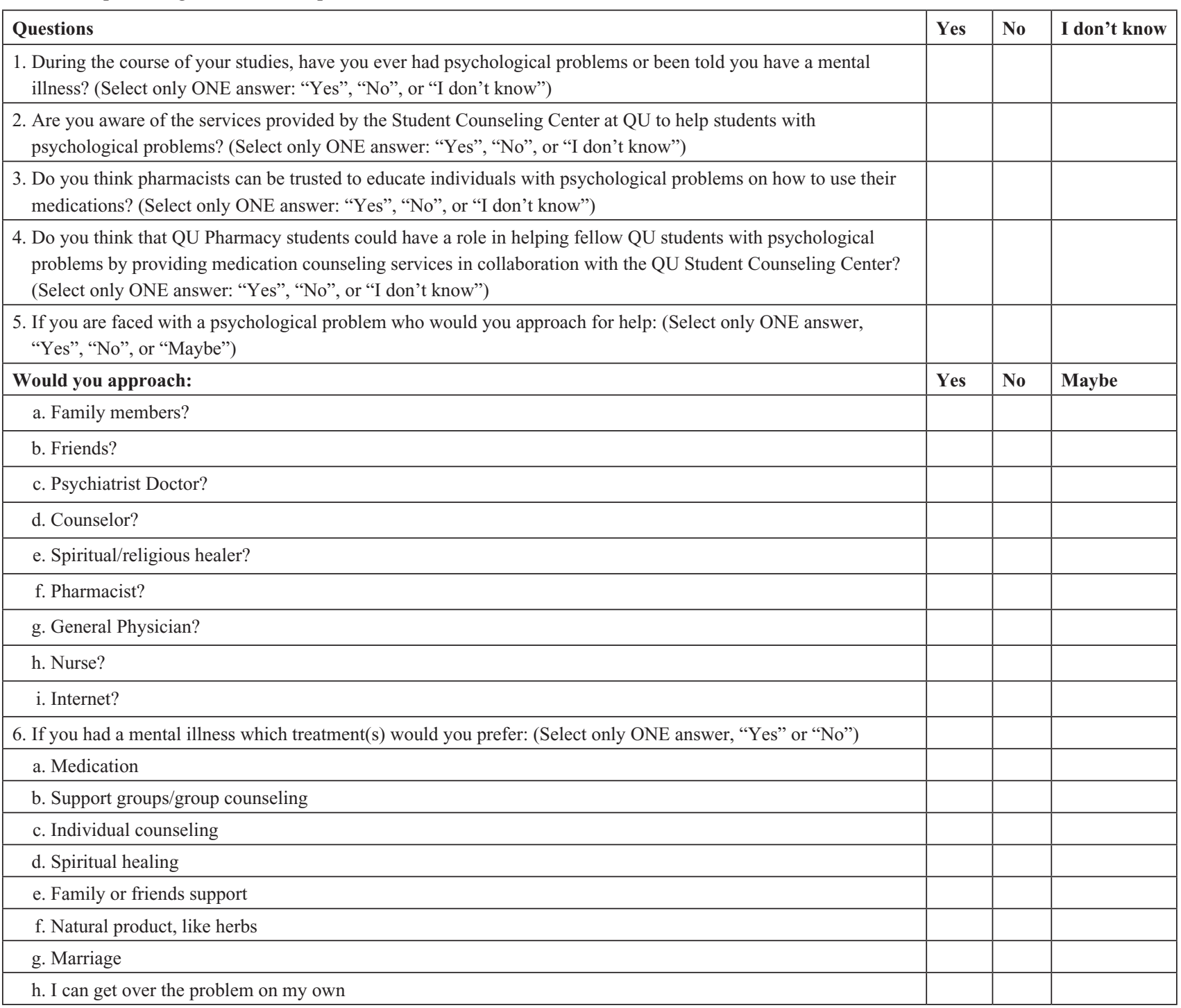

Thank you for completing the survey. 
Neuropsychiatric Disease and Treatment

Dovepress

\section{Publish your work in this journal}

Neuropsychiatric Disease and Treatment is an international, peerreviewed journal of clinical therapeutics and pharmacology focusing on concise rapid reporting of clinical or pre-clinical studies on a range of neuropsychiatric and neurological disorders. This journal is indexed on PubMed Central, the 'PsycINFO' database and CAS,

and is the official journal of The International Neuropsychiatric Association (INA). The manuscript management system is completely online and includes a very quick and fair peer-review system, which is all easy to use. Visit http://www.dovepress.com/testimonials.php to read real quotes from published authors.

Submit your manuscript here: http://www.dovepress.com/neuropsychiatric-disease-and-treatment-journal 